\title{
Design of reactive power procurement in deregulated electricity market
}

\author{
Archana Singh $^{1}$, D.S.Chauhan ${ }^{1 *}$, K.G.Upadhyay ${ }^{1 \#}$ \\ ${ }^{1}$ Electrical Engineering Department, H.B.T.I, Kanpur (U.P), INDIA 208002 \\ ${ }^{* 2}$ Institute of Technology, BHU, Varanasi (U.P.), INDIA 444605 \\ ${ }^{\# 1}$ M.M.M.E.C.,Gorakhpur(U.P.),INDIA \\ "Corresponding Author: Archana Singh, e-mail:archanasingheed@in.com
}

\begin{abstract}
Reactive power management is required to support real power shipment, providing reserve for voltage security and supplying reactive loads. Reactive power management is different in the deregulated electricity market of various countries. In this paper, a novel reactive power procurement model is proposed, which ensure secure and reliable operation of deregulated electricity market. Various issues of reactive power management in the deregulated electricity market have been discussed. A reactive power bid, reactive capability of a generator has been discussed in the context of procurement reactive power model. A twolevel framework of the reactive power is proposed. The first-level of the proposed model, i.e. reactive power procurement, to be done on (few months ahead)advance basis from real time operation with an objective of minimization of reactive generation cost followed by maximization of its Societal Advantage Function(SAF) while considering the second-level, i.e., reactive power dispatch in tandem with real-time operation. The IEEE 24-bus RTS test system is used to illustrate the proposed reactive power procurement. The offers of generation have been considered by minimization of reactive generation cost followed by maximization of Societal Advantage Function.
\end{abstract}

Keywords: Reactive Bids, Deregulation, Societal Advantage Function, Reactive Power Pricing, Cost of Opportunity Lost(LOC)

\section{Introduction}

Supply of reactive power has been identified as one of the keys ancillary services in the restructured electricity market. In recently published FERC report $(\mathrm{FERC}, 2005)$ it is suggested that an efficient pricing and procurement scheme for reactive power should encourage investment in the infrastructure needed to maintain the reliability of the transmission system and provide incentives for the reliable and efficient production and consumption of reactive power from the available infrastructure. In a deregulated electricity market, reactive power provision needs to be made by Independent System Operator (ISO) in order to meet contracted transaction in secure manner (Wang, 2004).

Often the independent generators or local suppliers own the resources for reactive power such as synchronous generators, synchronous condensers, capacitor banks, reactors, Flexible AC Transmission System (FACTS) devices. The reactive power management and payment mechanisms as an ancillary service vary for each deregulated electricity market of various countries in the way the contracts are framed and the markets are operated (Jhong, 2002). For example, the economic formulation has been proposed for optimal power flow real time computation of the reactive power marginal cost (Bhaugman, 1991). A two part reactive power spot pricing scheme is formulated in which one part accounts for investment cost of a new capacitor at a bus and second part is related with the variable spot price which accounts for the operating cost incurred in supplying the additional reactive power from generating units (Bhattacharya, 1995). Total cost of reactive power support is minimized, which includes the explicit cost from various transmission sources such as reactive compensators, tap-changing transformers and opportunity cost from various generation sources (Lemont, 1999).

A novel cost based modified OPF pricing scheme is formulated for reactive power with the assumption that the total reactive power can be divided into two parts. One is for real power transportation when there are no reactive loads in the system and other parts is for reactive power consumption, which is deemed as the responsibility of reactive loads (Dai,2004). The fair and accurate loss allocation scheme for real and reactive power loss was introduced in the bilateral market (Ki, 2006). The pattern of optimal 
load dispatch is considered as bi-level problem consisting of an upper and lower part the upper level problem is that of satisfying the demand functions where the prices are determined by the lower level problem which is basically the optimal power flow problem which has the objective of minimizing the total cost of operating the spatially separated generating units subject to the set of equations that characterize the flow of power throughout the system and all operational constraints (Lin,2003). Two prices corresponding to real load and reactive load of a consumer has been considered in the context of total cost recovery (Lin, 2005). Reactive power allocation is discussed in a reactive power market (Ki, 2006).

The design of a reactive power procurement model, as discussed in Singh (2010), is as two level approach in which first level is to optimal contracting of reactive power services by the ISO using the maximization of a societal advantage function. In the second level, reactive power dispatches to be close to real time operation.

\section{Reactive Power Management in various deregulated electricity markets}

There is no generalized reactive power management structure or design yet suggested due to variation of its concepts from one electricity market to another. This is discussed by the same author so only brief part is considered (Singh, 2009). In main countries like USA, UK, Australia, for procurement of reactive power services, the ISO enters into contracts with the reactive power providers. These contracts are usually traditional practices or bilateral agreements as per ISO experience for reactive power support. In the California, provision of reactive power services is based on long-term contracts between CaISO and reliable mustrun generators. In Canada, the Independent Electric System Operator (IESO) of Ontario requires generators to operate within a power factor range of 0.9 lag to 0.95 lead and within a $+/-5 \%$ range of its rated terminal voltage. The IESO sign's contracts with generators for reactive power support and voltage control, and generators are paid for the incremental cost of energy loss in the windings due to the increased reactive power generation. The generators are also paid an opportunity cost if they are required to generate reactive power levels by reduction of their real power dispatch. The generator receives payment at the market clearing price (Kirby,1997). The New York ISO (NYISO) compensate generators based on embedded cost pricing for their reactive power services, and also imposes a penalty for failing to provide reactive power (NY,1999). In NERC, reactive power provision from generators is mandated within a power factor range 0.9 lagging to 0.95 leading. Beyond these limits, the generators are paid for their reactive power including a loss opportunity cost payment (NERC, 2000).

In UK, the Transmission System Operator (TSO)-National Grid Company (NGC) invites half-yearly tenders from generators for "obligatory reactive power services" which correspond to the reactive power as each generator is required to provide, and "enhanced reactive power services" for generators with excess reactive power capabilities (NGET, 2006).

The payment in Australia (NEMCO, 1999) as follows:

- Availability Payments: All reactive support providers are eligible for the availability payment component for their preparedness to provide the service when called for.

- Enabling Payment: Synchronous compensators also receive the enabling payment component- paid when their service is activated by the ISO for use.

- Usage Payment: Based on actual use. Such as rapid loading and unloading services of generators.

- Compensation Payment: On the other hand, a generator receives the compensation payment component- which is based on its opportunity cost.

In the Sweden, contrary to other countries, reactive power services are provided on a mandatory basis from the synchronous generator, and so no financial compensation is provided.

Procurement of reactive power services through competition and long-term contracts between the ISO and service providers (generators) is an alternate way for reactive power management in deregulated electricity markets (Zhong, 2000,2002). Reactive power market has been considered more as a local market than a system-wide market (Zhong, 2004).

The present work extends the issue to the creation of a competitive market for reactive power services on the long term basis and illustrates proposed model with IEEE 24-bus test system. Short term framing concept is derived but due to paper limitation, it is not discussed in detail.

\section{Framework of Reactive Power Provision}

Reactive power provisions can also be framed as two classes of a problem in the context of deregulated electricity markets, namely,

- Reactive power procurement and

- Reactive power dispatch.

Reactive power procurement is basically a long-term issue, i.e., a seasonal problem; in this case, the ISO obtains optimal reactive power "allocations" from possible suppliers that would be best suited to its needs and constraints in a given season [El.Samahy, 2001]. This optimal set would be determined based on forecasts of the demand and system conditions expected over the planning horizon. The criterion for such procurement could be varied, but would essentially consider the cost/price offers of reactive power provision. This long term procurement can be done assuming like 60 days ahead on a season basis. The second level in the 
proposed approach to a reactive power provision is the short-term management function, which takes place one to half hour ahead of real-time.

A reactive power management scheme based on reactive power procurement versus its real time dispatch is proposed that comprises two major time-based steps (shown in Figure 1).

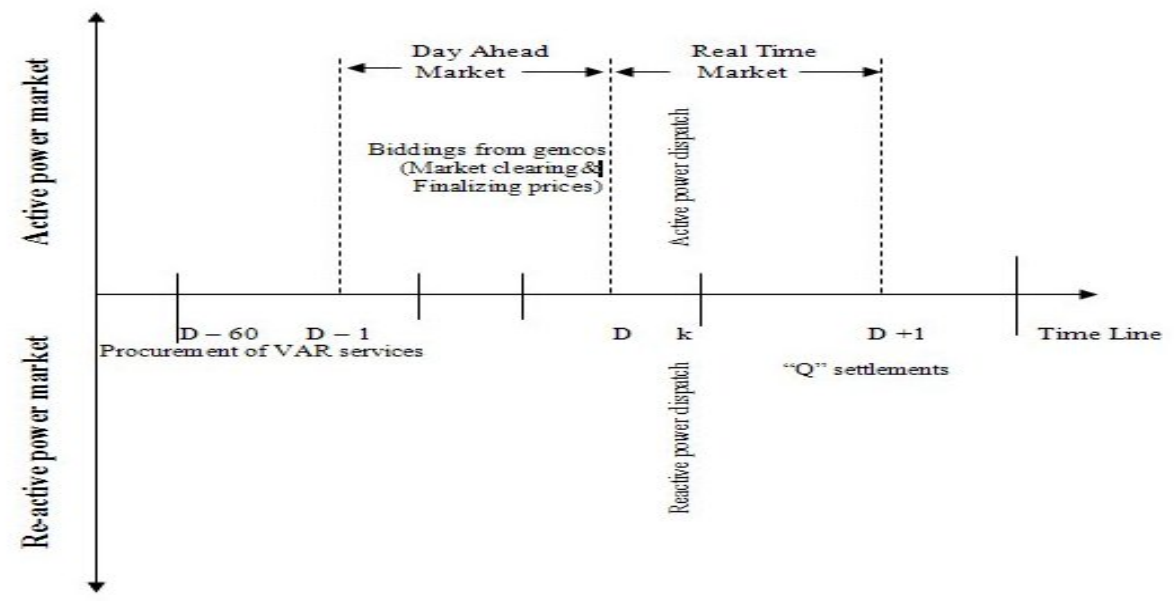

Figure1. Electricity market clearing and dispatch at day D hour k.

The Electricity market settlement is decoupled into two sub-problems as active and reactive OPF sub-problem of market settlement to avoid coupled market complexity. Active power sub-problem market provides real-time based the active power prices and dispatches with cost minimization along-with their social welfare maximization. Reactive power sub-problem market model provides reactive power levels and prices based on a taken optimization criterion operating in different time frames. A required flexibility for spot market application is provided by decoupling OPF problem retaining a sufficient level of accuracy. Figure 1 describes decoupling of active and reactive power markets keeping these two markets in entirely different operating time frames, so that the ISO does not entertain reactive power management in the same time frame as that of real power auctions. This basically reduces market inefficiencies and minimizes the risk that might arise from price volatility of real power.

\subsection{Reactive Power Procurement}

In the reactive power procurement, first reactive power offers from the reactive power providers are called and based on the received bids. An optimization model is solved, which maximizes a societal welfare function subject to system constraints. This optimization model yields the required reactive power service "reserves" for each generator along with the price components of reactive power. The selected providers would be receiving an availability payment for these reserves as a long-term obligation for the reactive power provision. The schematic representation of reactive power procurement in long term management mechanism is depicted in Figure 2. 


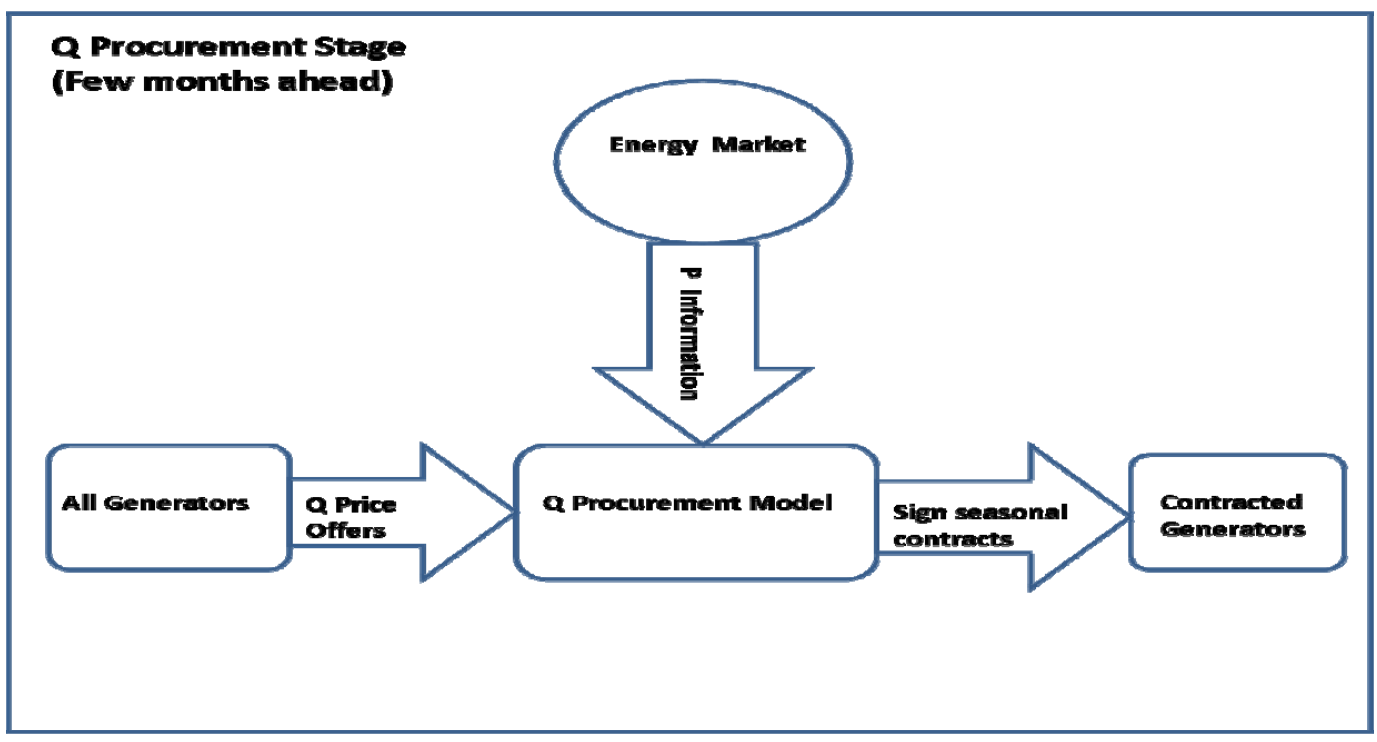

Figure 2. Long term management for Reactive Power Services

\subsubsection{Reactive Power limits of Synchronous Generator}

The point of intersection of the two curves formed with armature and field winding heating limits decides MVA rating of Synchronous Generator. The armature heating limit is taken in circle form with $R_{1}\left(\left(=V_{t} I_{a}\right)^{1 / 2}\right.$ radius, centre on $C_{1}(0,0)$. The field heating limit also forms a circle with $R_{2}\left(=V_{t} E_{a f} / X_{S}\right)$ radius, centre on $C_{2}\left(0,-V_{t}^{2} / X_{S}\right)$. ( as shown in figure3)

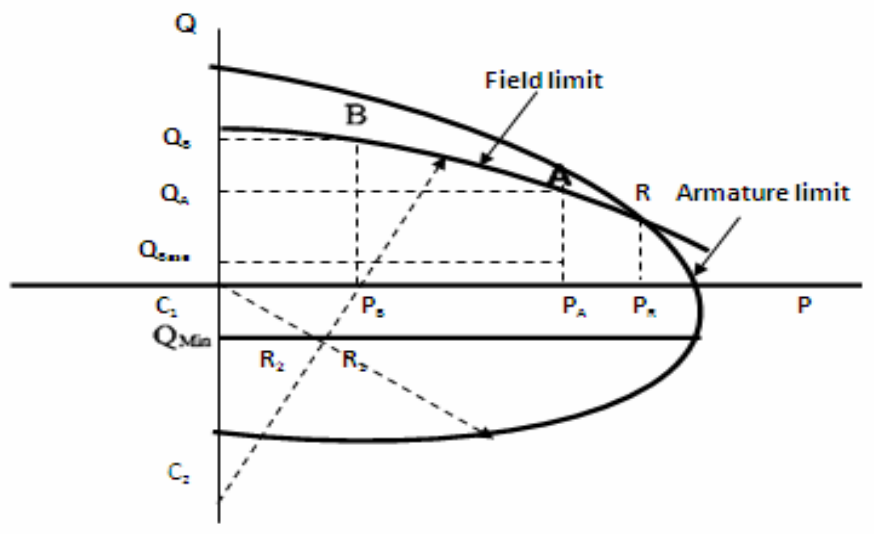

Figure3. Determination of Reactive Power limits from Generators

As per the capability curve (as shown in Figure 3), the generator requires minimum $Q_{\text {Base }}$ for its auxiliary equipment. The generator may increase its reactive generation from $Q_{B a s e}$ up to $Q_{A}$ without requiring readjustment of $P A$, If the operating point says, at $\left(\mathrm{P}_{\mathrm{A}}, \mathrm{Q}_{\mathrm{Base}}\right)$ lies inside the limiting curves. However, this will result in increased losses in the windings and so cost of losses increases. Any increase in $\mathrm{Q}$ beyond the limiting curve will require a decrease in $\mathrm{P}$ to adhere to field heating limits as per capability curve. Consider the operating point ' $A$ ' on the curve $\left(\mathrm{P}_{\mathrm{A}}, \mathrm{Q}_{\mathrm{A}}\right)$, the operating point requires shifting back along the curve to point $\mathrm{B}\left(\mathrm{P}_{\mathrm{B}}, \mathrm{Q}_{\mathrm{B}}\right)$, where $\mathrm{P}_{\mathrm{B}}<\mathrm{P}_{\mathrm{A}}$. This signifies that the unit has to reduce its real power output to adhere to field heating limits when higher reactive power demanded. Due to the reduced production of real power, loss in revenue is termed loss opportunity cost.

So three operating regions for a generator are defined, which are as follows:

Region-1: (When $\mathrm{Q}_{\mathrm{G}}=\mathrm{Q}_{1}$ lies between 0 and $\mathrm{Q}_{\min }$ )

It means the generator is absorbing reactive power within this region. It would incur a cost of loss for absorption.

Region-2: (When $\mathrm{Q}_{\mathrm{G}}=\mathrm{Q}_{2}$ lies between $\mathrm{Q}_{\text {Base }}$ and $\mathrm{Q}_{\mathrm{A}}$ )

Mandatory lagging behind reactive power is from 0 to $\mathrm{Q}_{\text {Base. }}$ It means that generator is injecting reactive power and so entitled for payment for the increased losses in the winding (Cost of loss component). 
Region-3: $\left(\right.$ When $\mathrm{Q}_{\mathrm{G}}=\mathrm{Q}_{3}$ lies between $\mathrm{Q}_{\mathrm{A}}$ and $\left.\mathrm{Q}_{\mathrm{B}}\right)$

Generator will be required to decrease active power generation and so eligible for cost payment of loss of opportunity.

\subsubsection{Structure of Reactive Power Offers from Generator:}

Based on the classification of reactive power production costs, an offer structure can be formulated (also shown in figure4.)

- Availability price offer $\left(\mathrm{a}_{0}, \$ / \mathrm{h}\right)$ : A fixed component to account for that portion of a supplier's capital cost that can be attributed to reactive power production.

- Cost of the loss offer $(\mathrm{m} 1, \mathrm{~m} 2, \$$ MVAr-h): An assumed linearly varying component to account for the increased winding losses as reactive power output increases, in the under- and over- excitation ranges, respectively.

- Opportunity offer $\left(\mathrm{m}_{3}, \$ / \mathrm{MVAr}-\mathrm{h} / \mathrm{MVAr}-\mathrm{h}\right)$ : A quadratic component to account for the lost opportunity cost when a supplier is constrained from producing its scheduled real power in order to increase its reactive power production.

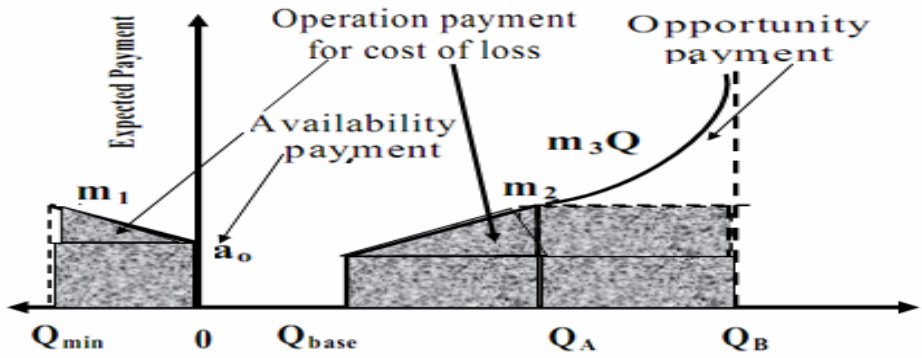

Figure 4. Reactive power offer structure of a generator

\subsubsection{Marginal Benefit of Reactive Power Supply from Synchronous Generator:}

Reactive Power output from a provider is classified into three regions $\left(Q_{\min }, 0\right),\left(Q_{\text {Base }}, Q_{A}\right)$ and $\left(Q_{A}, Q_{B}\right)$. It is considered as three components: Q1, Q2 or Q3 respectively and generator will provide their respective offer bids. Accordingly, only one of the binary variables $W_{1}, W_{2}$ or $W_{3}$ can be selected. The opportunity cost for Q3 is quadratic function as shown in figure 4 . Using the elementary mathematics we can derive the following cost function:

To minimize:

$$
\begin{aligned}
\text { Cost }= & \sum_{i=1}^{N G} \sum_{h=1}^{N H}\left(\rho_{0} \cdot W_{0, i, h}-\rho_{1} \cdot W_{1, i, h} \cdot Q_{1, i, h}+\rho_{2} \cdot W_{2, i, h}\left(Q_{2, i, h}-Q_{b a s e, i, h}+\right.\right. \\
& \rho_{2} \cdot W_{3, i, h}\left(Q_{3, i, h}-Q_{\text {base }, i, h}\right)+\frac{1}{2} \rho_{3} \cdot W_{3, i, h}\left[\left(Q_{3, i, h}^{2}\right)-\left(Q_{A, i, h}^{2}\right)\right]
\end{aligned}
$$

In eqn (1), if any generator is selected then $W_{0, i, h}$ will be 1 irrespective of its amount of reactive power output.

$W_{1, i, h}, W_{2, i, h}$ and $W_{3, i, h}$ are binary variables i.e. $\left[\left(W_{1, i, h}, W_{2, i, h}, W_{3, i, h}\right) \in\{0,1\}\right]$.

If $h^{\text {th }}$ supplier connected to $i^{\text {th }}$ bus is selected then $W_{0, i, h}$ will be equal to one so only one of the binary variables

$W_{1, i, h}, W_{2, i, h}$ or $W_{3, i, h}$ will be selected. It means only then

$$
W_{1, i, h}+W_{2, i, h}+W_{3, i, h}=1
$$

$\mathrm{NG}$ is group of generator and $\mathrm{NH}$ is representation of each supplier at a bus.

$Q_{1, i, h}, Q_{2, i, h}$ and $Q_{3, i, h}$ represent the regions $\left(Q_{\min , i, h}\right.$ to 0$),\left(Q_{b a s e, i, h}\right.$ to $\left.Q_{A, i, h}\right)$ and $\left(Q_{A, i, h}\right.$ to $\left.Q_{B, i, h}\right)$ i.e.

$Q_{i, h}=Q_{1, i, h}+Q_{2, i, h}+Q_{3, i, h}$

The system constraints are as follows:

The equality constraints of the OPF problem are as follows: 


$$
\begin{aligned}
& \sum_{h=1}^{N H_{i}} P_{G, i, h}-P_{D i}-\sum_{j \in N}\left|V_{i}\right|\left|V_{j}\right||Y i j| \cos \left(\theta_{i j}+\delta_{j}-\delta_{i}\right)=0 ; \forall i, h \in N G \\
& \sum_{h=1}^{N H_{i}} Q_{G i, h}-Q_{D i}-\sum_{j \in N}\left|V_{i}\right|\left|V_{j} \| Y i j\right| \sin \left(\theta_{i j}+\delta_{j}-\delta_{i}\right)=0 ; \forall i, h \in N G
\end{aligned}
$$

Where $N$ is the total number of buses in the system;

$P_{G i}, Q_{G i}, \mathrm{P}_{D i}, Q_{D i}$ are the active and reactive power generation and demand on bus i.

$Y_{i j} \angle \theta_{i j}$ is the element in the bus admittance matrix. $\dot{V}=V_{i} \angle \delta_{i}$ is the bus voltage at bus $i$.

The inequality constraints are:

1. Generation limits:

$$
P_{G i, \min } \leq P_{G i} \leq P_{G i, \max } \quad \mathrm{i} \in \mathrm{G}
$$

2. Reactive limits:

$$
Q_{G g \leq} Q_{G g}^{\max }, \forall g
$$

Where

$$
\begin{aligned}
& Q_{G}^{\max }=\sqrt{\left(V_{t} E_{a f} / X_{S}\right)^{2}-\left(P_{G}\right)^{2}-V_{t}^{2} / X_{S}} \text { for } P_{G}<P_{R} \\
& \text { or } \sqrt{\left(V_{t} I_{a}\right)^{2}-\left(P_{G}\right)^{2}} \text { for } P_{G}>P_{R} \\
& Q_{G g \geq} Q_{G g}^{\mathrm{min}}, \forall g
\end{aligned}
$$

3. Voltage Limits

$$
V_{i, \min } \leq\left|V_{i}\right| \leq V_{i, \max , \forall i}
$$

4. Transmission Limits:

$$
\left|\mathrm{P}_{\mathrm{ij}}\right| \leq P_{i j, \max } \quad i \neq j \text { and } \forall i, j
$$

Where

$$
P_{i j}=\left|V_{i}\right|\left|V_{j}\right||Y i j| \cos \left(\theta_{i j}+\delta_{j}-\delta_{i}\right)-\left|V_{i}\right|^{2}\left|Y_{i j}\right| \cos \theta_{i j}
$$

5. The constraints of generators for reactive power compensation

$$
\begin{gathered}
W_{2, i, h} \cdot Q_{\text {base }, i, h} \leq Q_{2, i, h} \leq W_{2, i, h} \cdot Q_{A, i, h} \\
W_{3, i, h} \cdot Q_{A, i, h} \leq Q_{3, i, h} \leq W_{3, i, h} \cdot Q_{B, i, h} \\
W_{1, i, h}+W_{2, i, h}+W_{3, i, h} \leq 1 \\
W_{1, i, h}+W_{2, i, h}+W_{3, i, h}=W_{0, i, h}
\end{gathered}
$$

6. Constraints for determination of uniform price offers of generators

$$
W_{0, i, h} \cdot a_{0, i, h} \leq \rho_{0} ; \forall i, h \in N G
$$




$$
\begin{aligned}
& W_{1, i, h} \cdot m_{1, i, h} \leq \rho_{1} \forall i, h \in N G \\
& \left(W_{2, i, h}+W_{3, i, h}\right) \cdot m_{2, i, h} \leq \rho_{2} \forall i, h \in N G \\
& W_{3, i, h} \cdot m_{3, i, h} \leq \rho_{3} \forall i, h \in N G
\end{aligned}
$$

In the above equations, Eqn (1) is cost minimization, eqn, Eqn (2) - (3) are considered as equality constraints of power balance equations. Eqn (4) to (8) are taken as inequality constraints and from eqn (9) to (16) are constraints of a generator for reactive power compensation and constraints for determination of uniform zonal price offers.

The basic cost function is referred from J. Zhong[3, 18,19,20], Bhattacharya [5], El-Samahy[21,22], Rabiee et al. (2009). In this paper their work has been extended and social welfare function is used for procurement of reactive power in long term market.

As mentioned above, reactive power procurement model is formed based on the marginal contributions of reactive power from generation cost minimization. In the result, the Lagrange multipliers that represent the marginal benefit/contribution of each reactive power source with respect to reactive cost minimization are $\lambda_{\mathrm{g}}, \gamma_{\mathrm{g}}$ and $\mu_{\mathrm{g}} . \lambda_{\mathrm{g}}$ denotes the sensitivity of the objective function to a change in system demand. Simply stated $\lambda$ denotes the change in the system cost for a $1 \mathrm{MW}$ in the system demand. The multiplier $\mu$ and $\gamma$ are associated with the generator limits and these are of significance only when a generator limit is a binding constraint. An important point can be stated here is that when the generating limit is not binding then $\mu=0$ and $\gamma=0$. All the three Lagrange multipliers will be zero for any generator as long as it lies within the limits specified, whereas will be a nonzero value for any generator if its touches the upper or lower limits of the respective region.

\subsubsection{Societal Advantage Function}

Once the reactive power, ancillary service limits and the marginal benefits of each provider with respect to reactive generation cost are determined, and reactive power offers are received, the ISO is in a position to carry out a procurement market settlement where its sole objective is to maximize a societal advantage function. The proposed SAF is formulated considering benefits accrued from reactive power services with respect to expected payment by the ISO. SAF is considered on a zonal basis and can be expressed as follows:

$$
\begin{aligned}
& S A F_{K}=-\sum_{g \in K} \rho_{0 K}+\sum_{g \in K}\left(c_{L} \mu_{g}-\rho_{1 K}\right) Q_{1 g}+\sum_{g \in K}\left(c_{L} \lambda_{g}-\rho_{2 K}\right)\left(Q_{2 g}-Q_{\text {baseg }}\right) \\
& +\sum_{g \in K}\left(\left(c_{L} \gamma_{g}-\rho_{2 K}\right)\left(Q_{3 g}-Q_{\text {baseg }}\right)-0.5 \rho_{3 K}\left[\left(Q_{3 g}-Q_{A g}\right)^{2}\right]\right.
\end{aligned}
$$

In (9),the the subscript $\mathrm{g}$ denotes set of generators in the zone $\mathrm{K}$ considering that the system is divided into zones. The variables $\rho 1 \mathrm{k}$ (in $\$$ MVAr-h) and $\rho 2 \mathrm{k}$ (in $\$$ /MVAr-h) are the under- and over-excitation prices for reactive power in the zone k, respectively; similarly $\rho 3 \mathrm{k}$ (in $\$ / M V A r-h / M V A r-h)$ is the zonal uniform opportunity price component. The variable pok (in \$) is the zonal availability price component. The constant $C_{L}$ is a "loadability" cost parameter (in $\$ / \mathrm{MWh}$ ) denoting the economic worth of increasing the system loadability. It is taken as $100 \$ / M W h$ in this paper.

The proposed procurement algorithm is based on the following OPF model:

Maximize SAF as given in eqn (17) with following constraints

1) Load flow (2), (3)

2) Reactive Power Generation limits (4), (5), (6)

3) Bus Voltage limits (7)

4) Power Transfer limit (8)

5) The constraints of generator (9), (10), (11), (12) and

6) Constraints for price offer (13), (14), (15), (16).

The solution of the above procurement model yields the set of contracted generators as well as the zonal uniform price components after its maximization of societal advantage function.

\subsection{Reactive Power Dispatch}

The second level in the proposed hierarchical approach to reactive power management is the short-term management function, which takes place one to half hour ahead of real-time. The real-time dispatch of reactive power only takes into account the current operating conditions, with the ISO arriving at the optimal dispatch via an OPF (shown in Figure5). Based on actual usage and actually dispatch requested, cumulative payment to a supplier is calculated post real time operation. 


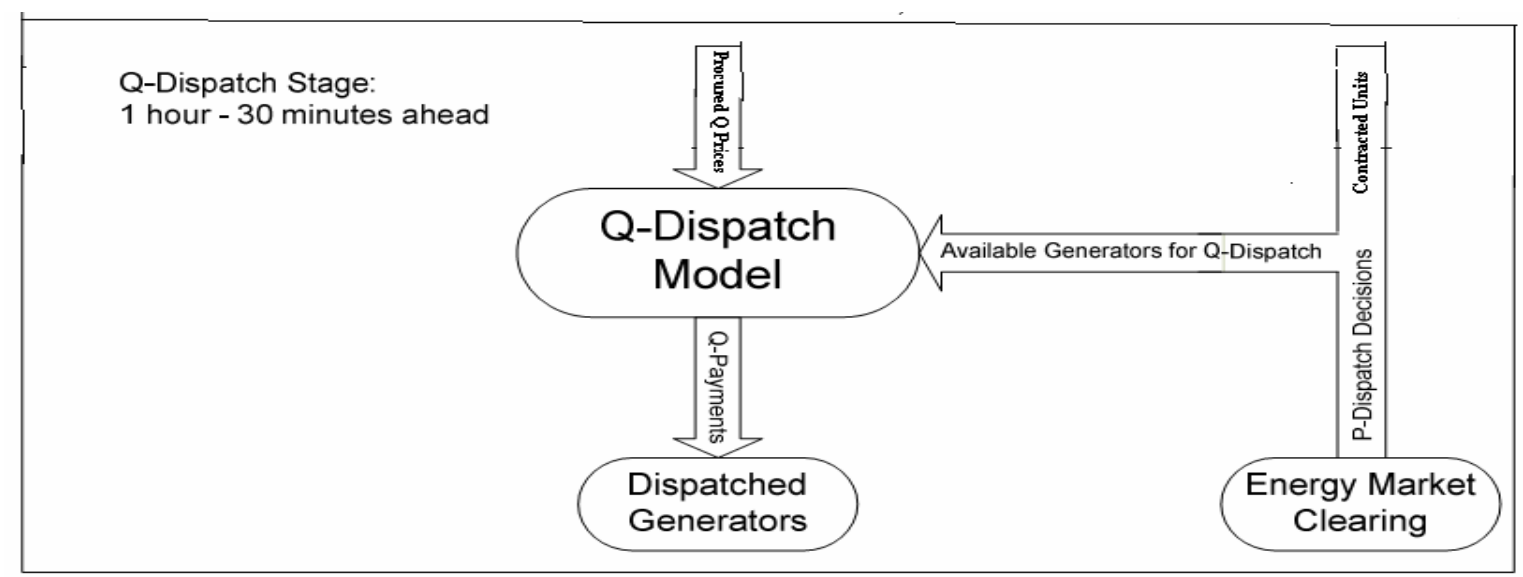

Figure5. Reactive power dispatch (short term management)

\section{Maximization of Societal Advantage Function in Reactive Power Procurement}

It is important to mention that the solution for above problem formulation is Non Linear Programming solution. The main objective is to choose only one region of reactive power operation to satisfy the conditions associated with the quadratic term and the constraints. $\lambda, \gamma$ and $\mu$ are the Lagrange multipliers obtained from the optimization model of marginal benefits of reactive power supply. Final optimization is done to maximize Societal Advantage Function in terms of ISO to provide high performance contribution to the system from generators with minimum payment burden. The flow chart for SAF is as follows:

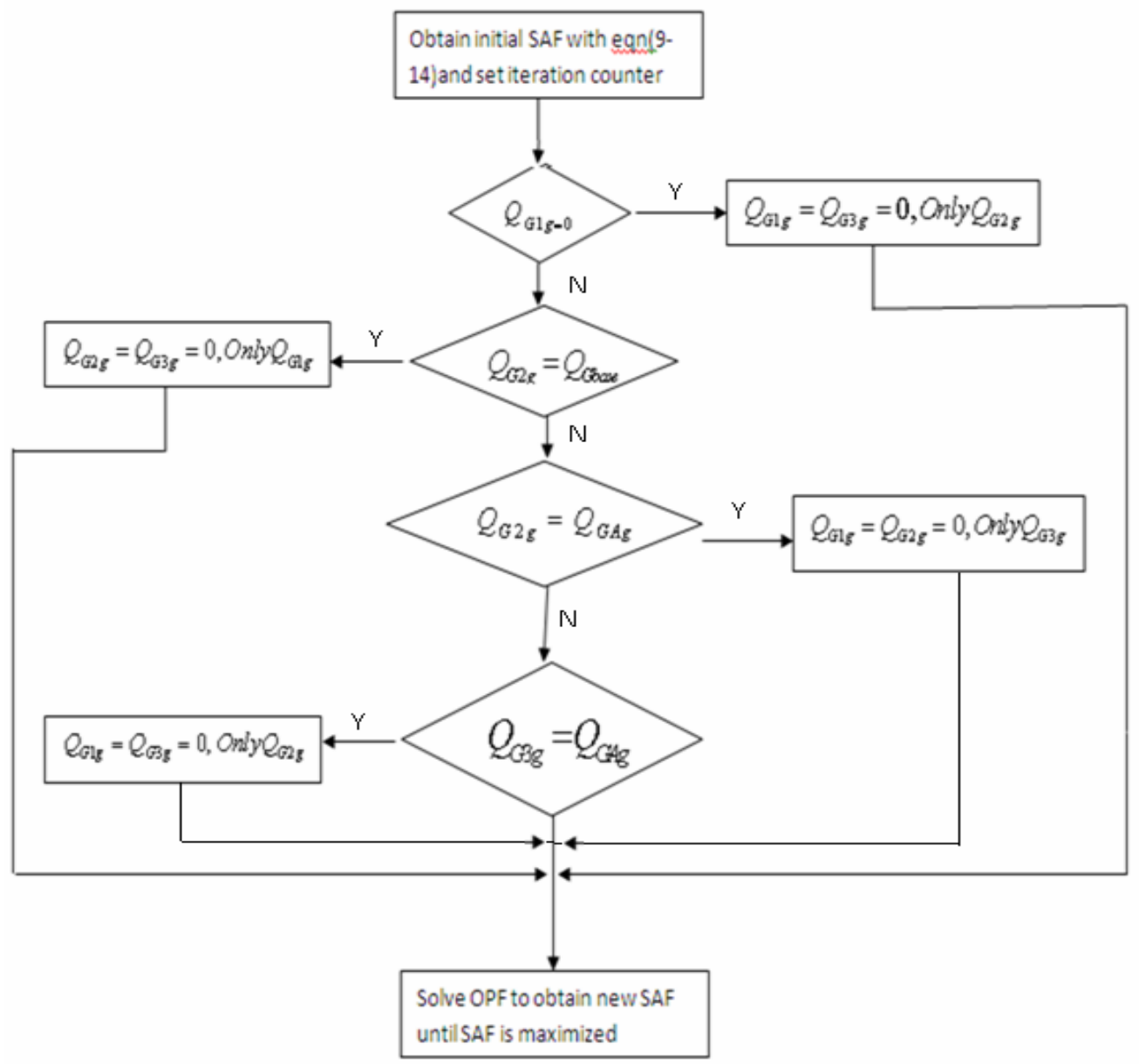

Figure 6. Maximization of SAF with reactive power procurement 
The objective is to maximize SAF based on values found of $\lambda, \gamma$ and $\mu$ alongwith values of Q1, Q2 and Q3. At first initial SAF is calculated. For generator, check if $\mathrm{Qg}$ hits the limits in any region like if $\mathrm{Qg}=\mathrm{Qg}_{2 \max }$ of region II then considers $\mathrm{Qg}$ in region III and resolve SAF-optimization eqn(9 to 14).This way updation is applied with the condition that SAF is maximized.

\section{Implementation and Results}

The simulation is performed in the Matlab. The input parameters are given in nomenclature.The results in terms of marginal benefit are shown in Table 1 and final results are shown in Table 3. Reactive power procurement scheme is tested on the IEEE 24 bus (RTS) system [IEEE RTS] shown in figure7. There are 32 synchronous generators, 1 synchronous condenser (located at bus 14) and 17 constant -power type loads. The participants of decoupled reactive power market are supposed to submit their four components of the offer prices $(\mathrm{a} 0, \mathrm{~m} 1, \mathrm{~m} 2, \mathrm{~m} 3)$ (Rabiee, 2009). The participants are also required to send their $Q_{\min }, Q_{\text {Base }}, Q_{\max }$.In this paper, $Q_{\text {base }}=0.1 \times Q_{\max }$ and $Q_{A}=0.8 \times Q_{B}$ are considered. This is a non-linear programming (NLP) problem. The simulation is performed in Matlab. In this paper, Fmincon is used to solve nonlinear constrained objective. Fmincon is an optimization tool in Matlab. Fmincon attempts to find a constrained minimum of a scalar function of several variables starting at an initial estimate. This is generally referred to as constrained nonlinear optimization or nonlinear programming. Fmincon finds the minimum of constrained nonlinear multivariable function. Fmincon minimizes the function of more than one variable subject to constraints that the specified function of the solution should be positive or zero. The first step is to calculate $\lambda, \gamma$ and $\mu$ for each generator by solving the OPF model. All Qg values are in p.u. with respect to a base value of 100 MVA.

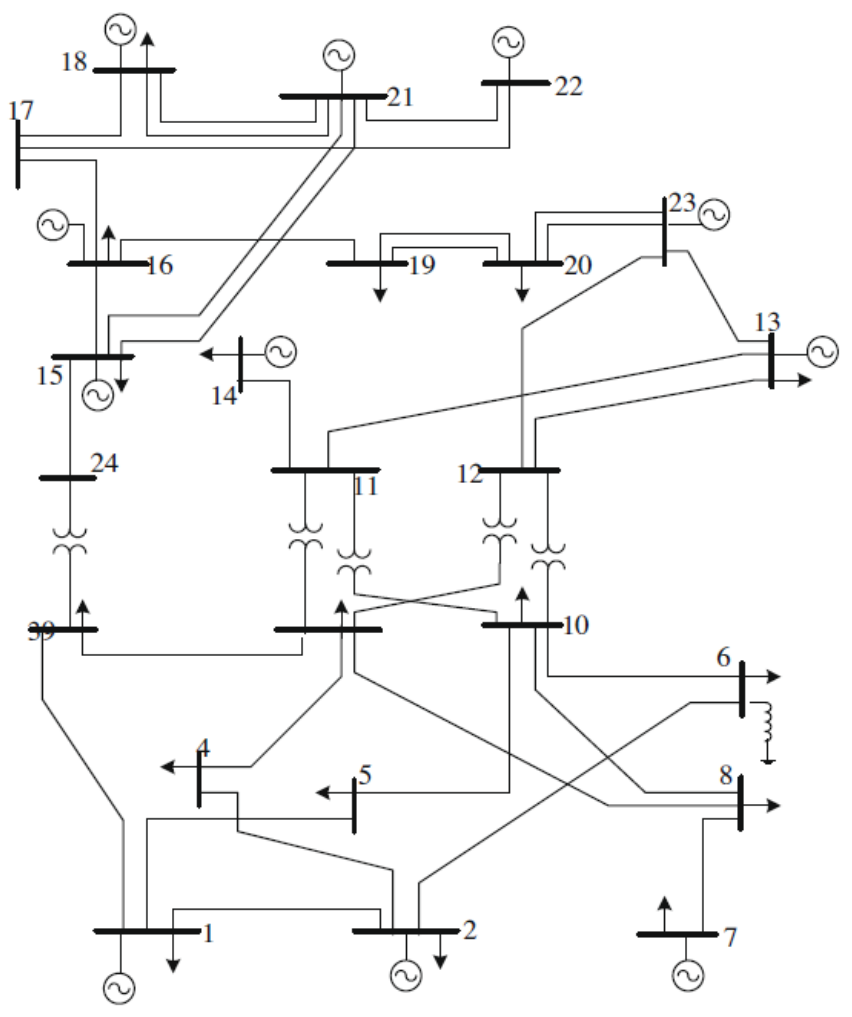

Figure 7. IEEE 24-Bus RTS system

Table 1 shows offer data for all the generators. The solution is given in Table 2. It is clear that Qg can only take one of the three values corresponding to the region of operation of respective generator and so regions are shown in the Table 2. The second step is to solve OPF that maximizes Societal Advantage function using values of first step and Qg. The final solutions of OPF problem are given in Table 2, where the total cost payment to generators is given along with final price offers as uniform availability price, under-excitation price and over-excitation price respectively. The optimal value of the objective function $S_{W}$ is $134 \$$. 
Table 1: Reactive Power contract offer prices of 24 Bus (RTS) IEEE system

\begin{tabular}{|c|c|c|c|c|c|}
\hline $\begin{array}{c}\text { Bus } \\
\text { no. }\end{array}$ & Unit no. & $a_{0}^{i, u}(\$)$ & $m_{1}^{i, u}(\$ / M V A r-h)$ & $m_{2}^{i, u}(\$ / M V A r-h)$ & $m_{3}^{i, u}(\$ / M V A r-h / M V A r-h)$ \\
\hline 1 & 1 & 0.96 & 0.86 & 0.86 & 0.46 \\
\hline 1 & 2 & 0.94 & 0.82 & 0.82 & 0.45 \\
\hline 1 & 3 & 0.85 & 0.79 & 0.79 & 0.39 \\
\hline 1 & 4 & 0.83 & 0.82 & 0.82 & 0.40 \\
\hline 2 & 1 & 0.50 & 0.54 & 0.54 & 0.28 \\
\hline 2 & 2 & 0.42 & 0.42 & 0.42 & 0.35 \\
\hline 2 & 3 & 0.69 & 0.68 & 0.68 & 0.39 \\
\hline 2 & 4 & 0.65 & 0.62 & 0.62 & 0.37 \\
\hline 7 & 1 & 0.75 & 0.61 & 0.61 & 0.43 \\
\hline 7 & 2 & 0.80 & 0.75 & 0.75 & 0.36 \\
\hline 7 & 3 & 0.70 & 0.65 & 0.65 & 0.32 \\
\hline 13 & 1 & 0.68 & 0.50 & 0.50 & 0.31 \\
\hline 13 & 2 & 0.70 & 0.54 & 0.54 & 0.39 \\
\hline 13 & 3 & 0.75 & 0.60 & 0.60 & 0.50 \\
\hline $14^{*}$ & 1 & 0.94 & 0.81 & 0.81 & 0.00 \\
\hline 15 & 1 & 0.65 & 0.60 & 0.60 & 0.30 \\
\hline 15 & 2 & 0.50 & 0.58 & 0.58 & 0.25 \\
\hline 15 & 3 & 0.60 & 0.73 & 0.73 & 0.38 \\
\hline 15 & 4 & 0.55 & 0.61 & 0.61 & 0.27 \\
\hline 15 & 5 & 0.52 & 0.50 & 0.50 & 0.26 \\
\hline 15 & 6 & 0.51 & 0.51 & 0.51 & 0.27 \\
\hline 16 & 1 & 0.50 & 0.50 & 0.50 & 0.30 \\
\hline 18 & 1 & 0.90 & 0.85 & 0.85 & 0.48 \\
\hline 21 & 1 & 0.80 & 0.75 & 0.75 & 0.41 \\
\hline 22 & 1 & 0.42 & 0.42 & 0.42 & 0.17 \\
\hline 22 & 2 & 0.50 & 0.48 & 0.48 & 0.20 \\
\hline 22 & 3 & 0.45 & 0.42 & 0.42 & 0.38 \\
\hline 22 & 4 & 0.48 & 0.44 & 0.44 & 0.35 \\
\hline 22 & 5 & 0.49 & 0.45 & 0.45 & 0.33 \\
\hline 22 & 6 & 0.55 & 0.46 & 0.46 & 0.32 \\
\hline 23 & 1 & 0.90 & 0.85 & 0.85 & 0.48 \\
\hline 23 & 2 & 0.95 & 0.89 & 0.89 & 0.55 \\
\hline 23 & 3 & 0.86 & 0.80 & 0.80 & 0.45 \\
\hline
\end{tabular}

* Synchronous Condenser (SC)

Table 2: After Cost minimization, the values of $\lambda, \gamma, \mu$ and $\mathrm{Q}_{\mathrm{G}}$

\begin{tabular}{|c|c|c|c|c|c|c|c|c|c|}
\hline \multirow{2}{*}{$\begin{array}{l}\text { Buses } \\
\text { having } \\
\text { Generators }\end{array}$} & \multicolumn{3}{|c|}{$\begin{array}{l}\text { Lagrange multipliers from cost } \\
\text { minimization }\end{array}$} & \multirow[b]{2}{*}{$\mathrm{Q}_{\mathrm{G}}$} & \multicolumn{3}{|c|}{ Classification of regions of $\mathrm{Q}_{\mathrm{G}}$} & \multirow[t]{2}{*}{$\mathrm{Q}_{\mathrm{G}}^{\max }$} & \multirow[t]{2}{*}{$\mathrm{Q}_{\mathrm{G}}{ }^{\min }$} \\
\hline & $\lambda$ & $\gamma$ & $\mu$ & & $\mathrm{Q}_{1}$ & $\mathrm{Q}_{2}$ & $\mathrm{Q}_{3}$ & & \\
\hline 1 & .04961 & .049589 & 0 & 4.07709 & 0 & 4.07709 & 0 & 10 & 0 \\
\hline 1 & .04961 & .049587 & 0 & 4.07709 & 0 & 4.07709 & 0 & 10 & 0 \\
\hline 1 & .04961 & .049588 & 0 & -0.78852 & -0.78852 & 0 & 0 & 30 & -25 \\
\hline 1 & .04961 & .049588 & 0 & -0.78852 & -0.78852 & 0 & 0 & 30 & -25 \\
\hline 2 & .05085 & 0 & .049687 & 8.640155 & 0 & 8.640155 & 0 & 10 & 0 \\
\hline 2 & .05085 & 0 & .049687 & 8.640155 & 0 & 8.640155 & 0 & 10 & 0 \\
\hline 2 & .05085 & 0 & 0 & -6.752158 & -6.752158 & 0 & 0 & 30 & -25 \\
\hline 2 & .05085 & 0 & 0 & -6.752158 & -6.752158 & 0 & 0 & 30 & -25 \\
\hline 7 & .050398 & .05112 & 0 & 16.43847 & 0 & 16.43847 & 0 & 60 & 0 \\
\hline 7 & .050398 & .05112 & 0 & 16.43847 & 0 & 16.43847 & 0 & 60 & 0 \\
\hline 7 & .05039 & .05112 & 0 & 16.43847 & 0 & 16.43847 & 0 & 60 & 0 \\
\hline 13 & .05017 & 0 & 0 & 32.59147 & 0 & 32.59147 & 0 & 80 & 0 \\
\hline 13 & .05017 & 0 & 0 & 32.59147 & 0 & 32.59147 & 0 & 80 & 0 \\
\hline 13 & .05017 & 0 & 0 & 32.59147 & 0 & 32.59147 & 0 & 80 & 0 \\
\hline
\end{tabular}


Table 2 (cont'd): After Cost minimization, the values of $\lambda, \gamma, \mu$ and $\mathrm{Q}_{\mathrm{G}}$

\begin{tabular}{|c|c|c|c|c|c|c|c|c|c|}
\hline \multirow{2}{*}{$\begin{array}{l}\text { Buses } \\
\text { having } \\
\text { Generators }\end{array}$} & \multicolumn{3}{|c|}{$\begin{array}{l}\text { Lagrange multipliers from cost } \\
\text { minimization }\end{array}$} & \multirow[b]{2}{*}{$\mathrm{Q}_{\mathrm{G}}$} & \multicolumn{3}{|c|}{ Classification of regions of $\mathrm{Q}_{\mathrm{G}}$} & \multirow[t]{2}{*}{$\mathrm{Q}_{\mathrm{G}}^{\max }$} & \multirow[t]{2}{*}{$\mathrm{Q}_{\mathrm{G}}{ }^{\min }$} \\
\hline & $\lambda$ & $\gamma$ & $\mu$ & & $\mathrm{Q}_{1}$ & $\mathrm{Q}_{2}$ & $\mathrm{Q}_{3}$ & & \\
\hline 15 & .04780 & 0 & .048045 & 6 & 0 & 0 & 6 & 6 & 0 \\
\hline 15 & .04781 & 0 & .048045 & 6 & 0 & 0 & 6 & 6 & 0 \\
\hline 15 & .04781 & 0 & .048045 & 6 & 0 & 0 & 6 & 6 & 0 \\
\hline 15 & .04781 & 0 & .048045 & 6 & 0 & 0 & 6 & 6 & 0 \\
\hline 15 & .04781 & 0 & .048045 & 6 & 0 & 0 & 6 & 6 & 0 \\
\hline 15 & .04781 & 0 & .048045 & 80 & 0 & 0 & 80 & 80 & -50 \\
\hline 16 & .045239 & 0 & .050851 & 80 & 0 & 0 & 80 & 80 & -50 \\
\hline 18 & .04756 & 0 & .046575 & 72.898438 & 0 & 72.898438 & 0 & 200 & -50 \\
\hline 21 & .0489983 & 0 & 0 & -7.458590 & -7.458590 & 0 & 0 & 200 & -50 \\
\hline 22 & .0495877 & .04783 & 0 & -6.413298 & -6.413298 & 0 & 0 & 16 & -10 \\
\hline 22 & .0495877 & .04783 & 0 & -6.413298 & -6.413298 & 0 & 0 & 16 & -10 \\
\hline 22 & .0495877 & .04783 & 0 & -6.413298 & -6.413298 & 0 & 0 & 16 & -10 \\
\hline 22 & .0495877 & .04783 & 0 & -6.413298 & -6.413298 & 0 & 0 & 16 & -10 \\
\hline 22 & .0495877 & .04783 & 0 & -6.413298 & -6.413298 & 0 & 0 & 16 & -10 \\
\hline 22 & .0495877 & .04783 & 0 & -6.413298 & -6.413298 & 0 & 0 & 16 & -10 \\
\hline 23 & .0510717 & .05181 & 0 & 11.957806 & 0 & 11.957806 & 0 & 80 & -50 \\
\hline 23 & .0510717 & .05181 & 0 & 11.957806 & 0 & 11.957806 & 0 & 80 & -50 \\
\hline 23 & .0510717 & .05181 & 0 & 21.727909 & 0 & 21.727909 & 0 & 150 & -25 \\
\hline
\end{tabular}

Table 3: Final reactive power offer prices and generator reactive power cost payment

\begin{tabular}{|l|l|}
\hline Generator Payment cost after its cost minimization $(\$ / \mathrm{h})$ & $6.3352 \mathrm{e}+004$ \\
\hline Availability price $(\rho 0)\left(\right.$ MCP for $\left.\mathrm{a}_{0}\right)$ in $\$$ & 0.96 \\
\hline Under-excitation price $(\rho 1)($ MCP for $\mathrm{m} 1)$ in $\$$ MVAr-h & 0.89 \\
\hline Over-excitation price $(\rho 1)($ MCP for $\mathrm{m} 2)$ in $\$$ MVAr-h & 0.89 \\
\hline Opportunity price $(\rho 3)($ MCP for $\mathrm{m} 3)$ in $\$$ MVAr-h/MVAr-h & 0.00 \\
\hline
\end{tabular}

\section{Conclusions}

The main objective of this paper is to design reactive power procurement market model in a deregulated electricity market. The proposed market design consists of two stages, namely, procurement of reactive power from generators on a long term(few month ahead) basis, and a real-time reactive power dispatch (short term stage)which is done in tandem with real time market. The main focus of this paper is a reactive procurement market model, which is a basically two-step optimization process. The first step determines marginal benefits of reactive power with respect to reactive generation cost considering all equality and enquality constraints. Results are then used in the second step to maximize a reactive power societal advantage function (SAF) considering bids from each service provider. In the second level, reactive power dispatch be close to real time operation. Result gives set of generators \& uniform price offers that would form a basis of contractual agreement for a reactive power provision with maximization of societal advantage function. In the future we are planning to extend this work for different operating conditions and loading parameters. 


\section{Nomenclature}

Symbol
P1k (in $\$ / M V A r-h)$
P2k(in $\$ / M V A r-h)$
P3k(in $\$ / M V A r / M V A r-h)$
pok (in $\$ / h)$
$\mathrm{C}_{\mathrm{L}}$ (in $\left.\$ / \mathrm{MWh}\right)$
$Q_{G g}$ in p.u.
$P_{G g}$ in p.u.
$\mathrm{V}_{\mathrm{t}}$ in p.u.
$\mathrm{E}_{\mathrm{a}}$ in p.u.
$\mathrm{X}_{\mathrm{s}}$
$V_{i, \min }$
$V_{i, \max }$
$\lambda_{\mathrm{g}}$
$\gamma_{\mathrm{g}}$
$\mu_{\mathrm{g}}$
$\mathrm{P}_{\mathrm{r}}$

\section{Description}

over-excitation prices for reactive power in zone $\mathrm{k}$

under-excitation prices for reactive power in zone $\mathrm{k}$

zonal uniform opportunity price component

zonal availability price component

economic worth of increasing the system loadability

Reactive power generation of generator at bus $g$

Active Power generation at bus $\mathrm{g}$

Terminal voltage of generator $g$ at which its capability curves are calculated

Excitation voltage of generator $g$ in p.u

Synchronous reactance of generator $g$

Minimum allowable voltage at bus $\mathrm{i}$

Maximum allowable voltage at bus $\mathrm{i}$

Dual of the reactive power balance constraint (3)

Dual of reactive power constraint of generator (5)

Dual of the under-excitation constraint (6)

Reactive power prices

Rated power of the generator
Value

100 input parameter

input parameter

input parameter

input parameter

input parameter

input parameter

input parameter

\section{References}

Baughman M.L., Siddiqi S.N., 1991. Real time pricing of reactive power: theory and case results, IEEE Transaction on Power Systems, Vol.6, No.1, pp.23-29.

Bhattacharya K., Chattopadhyay D. and Parikh J., 1995. Optimal reactive power planning and its spot pricing, an integrated approach. IEEE Transactions on Power Systems, Vol.10, No.4, pp.2014-2020.

Dai Y., Ni Y.X., Wen F.S. \& Hen Z.X., 2004. Analysis of reactive power pricing under deregulation. Proc. Of Power Engineering Society, Summer Meeting, Vol4, p. 2162-2167.

El-Samahy, K. Bhattacharya, and C. A. Cañizares, 2006. A unified framework for reactive power management in deregulated electricity markets, in Proc. IEEE-Power Eng. Soc. Power Systems Conf. Expo.(PSCE), Atlanta, GA.

El-Samahy ,K.Bhattacharya, and C.Canizares,2006. A heuristic method for reactive power service procurement, IEEE Mediterranean Electro technical Conference, Melecon, pp. 920-923.

FERC Staff.2005. Principles for efficient and reliable reactive power supply and consumption, Federal Energy Regulatory Commission ,N.E. Washington ,Staff Report ,Docket No.AD05-1-000.

IEEE Reliability Test System, 1979. A report prepared by the Reliability Test System Task Force of the Applications of Probability Methods Subcommittee, IEEE Trans. On Power Apparatus and Systems, Vol. PAS-98,pp.2047-2054.

Lemont J.W., Fu J., 1999. Cost analysis of reactive power support. IEEE transactions on Power Systems, Vol.14, No.3, pp.12261231.

Lo K.L.,Alturki YA, Toward reactive power markets. Part 1:reactive power allocation ,IEEE Proc Gener Trans Distrib 2006, Vol. 153, No. 1, pp. 59-70.

Lin X.J., Yu C.W., David A.K., Chung C.Y., 2003. Market mechanism for reactive power management, proceed. of APSCOM, p.593-600, China.

Lin X.J., Yu C.W., Chung C.Y. Pricing of reactive support ancillary services. IEEE Proc Gener Trans Distrib 2005; Vol. 152, No. 5, pp. 616-622.

Kirby B. and E. Hirst,1997. Ancillary Service Details: Voltage Control, ORNL/CON453, Oak Ridge National Laboratory, Oak Ridge, Tenn..

National electricity market ancillary services,1999. National Electricity Market Management Company (Australia),Version1.0,available from:http://www.nemco.com.au.

New York Independent system Operator Ancillary Services Manual, 1999.

Operating Policy 10-on Interconnected Operation Services. North American Electric Reliability Council (NERC), Draft-3.1, Issued Feb.2000.

Rabiee A., Shayanfar H. and Amjady N., 2009. Multiobjective clearing of reactive power market in deregulated power systems, Applied Energy, Vol. 86, No. 9, pp. 1555-1564. 
Singh A., Kalra P.K., Chauhan D.S., 2010. A novel procurement market model approach of reactive power in deregulated electricity market. International Journal of Recent Trends in Engineering, ACEEE, Finland, Vol 2., No.1, pp. 362-366.

Singh A.,P.K.Kalra,D.S.Chauhan,2009. New Approach of Procurement Market Model for Reactive Power in Deregulated Electricity Market, Proc. of Third International Conference on Power System(ICPS-09) at IIT,Kharagpur,Dec 27-29.

The connection and use of system code (CUSC). National Grid Electricity Transmission (NGET) plc,Issued Feb.2006.

Wang J, Wen R.G., Yang R.S..Onthe procurement and pricing of reactive power service in the electricity market environment. In: IEEE Power Engineering Society General Meeting 2004; Vol 1, pp. 1120-1124.

Zhong J., Bhattacharya K., 2002. Reactive power management in deregulated electricity market-A review. In Proc. IEEE Power Eng. Soc. Winter Meeting, Vol.2, pp.1287-1292.

Zhong J., Bhattacharya K. and Daalder J., 2000. Reactive power as an ancillary service: Issues in optimal procurement, in Proc.Int.Conf.Power System Technology, Vol.2, pp.885-890.

Zhong J. and Bhattacharya K., 2002. Toward a competitive market for reactive power, IEEE Trans. Power Syst.vol.17, pp.12061215.

Zhong J, Nobile E, Bose A., Bhattacharya K.Localized reactive power markets using the concept of voltage control areas. IEEE trans, Power Syst, 2004, Vol. 19, No. 3, pp. 1555-1561.

\section{Biographical Notes}

Archana Singh is Assistant Professor in the department of Electrical Engineering, HBTI, Kanpur, India. is engaged in teaching and research activities for the more than seven years. Her fields of interests are Restructured Electricity Market, Reactive Power Pricing, Power Trading. She is Associate Member of IE (India) IE (India and life time member of ISTE (India).

Dr. D.S. Chauhan is Professor, Department of Electrical Engineering, IT, Banaras Hindu University,Varanasi,U.P.,India. Presently he is Vice-Chancellor of Uttarakhand University, UK. He is engaged in teaching and research activities since the last 35 years. His fields of interest are Power System restructuring, Power Quality, HVDC, Neural Network. Network. Dr. D.S.Chauhan has published several papers in various national, international conferences and journals. He is a fellow of IE(India),fellow of IETE(India) IETE(India and senior member of IEEE.

Dr. K.G.Upadhyay is Professor and Head of Electrical Engineering in M.M.M.E.C. Gorakhpur (U.P.), India. He is engaged in teaching and research activities for the last more than 22 years. His research interests include power systems operation and control, FACTs and deregulation.

$\mathrm{He}$ is a fellow of IETE(India), member of Institution of Engineers (India) and ISTE.

Received January 2011

Accepted March 2011

Final acceptance in revised form April 2011 